\title{
La gestión positiva del conflicto en la economía social. Los MASC como vía generadora de bienestar empresarial ${ }^{\star}$ \\ Conflict positive management in the social economy environment. \\ Business welfare by adr procedure \\ A gestão positiva do conflito na economia social. Los MASC como via geradora de bem-estar empresarial
}

\author{
Jorge Palmer Marrero ${ }^{1}$ \\ (iD http://orcid.org/0000-0001-6441-5107 \\ Emilia Iglesias Ortuño \\ (D) http://orcid.org/0000-0002-1033-4907 \\ Universidad Autónoma de Zacatecas, México
}

DOI: http://dx.doi.org/10.21803\%2Fpenamer.10.19.462

Resumen

La economía social surge como respuesta a la necesidad de transformar el sistema económico tradicional incorporando la concepción social. Reconoce al individuo y motiva sus interacciones para favorecer su desarrollo personal y profesional. Estas interacciones con grupos, secciones, equipos o sociedades son susceptibles de derivar en situaciones de conflicto que precisan respuestas acordes a la filosofía de la entidad, filosofía que en el caso de las empresas de la economía social debe estar en consonancia con sus valores de autorrealización, solidaridad, igualdad, reparto de responsabilidades y responsabilidad. Los Métodos Alternos de Solución de Conflictos favorecen la autodeterminación, persiguen la igualdad de poder y buscan la autocomposición, elementos que se asemejan a los valores de la economía social, por lo que nos hace pensar que la combinación de ambos sistemas generará un sistema empresarial modernizado, humano, acorde a las demandas sociales y capaz de ofrecer alternativas que favorezcan el Bienestar social.

Palabras clave: Economía social, Métodos alternos de solución de conflictos, Capital humano, Responsabilidad social, Bienestar empresarial.

Abstract

Social Economy responses of the needs of transform the traditional economic system incorporating the social conception. Social Economy recognizes the individual and encourages their interactions to promote their personal and professional development. These interactions with groups, sections, teams or societies are likely to lead to conflict a situation that requires responses according to the philosophy of the organization, philosophy that in the case of companies of Social Economy should be in line with its values of self-realization, solidarity, equality, sharing of responsibility and accountability. Alternative Methods of Conflict Resolution favor self-determination, pursue equal power and seek auto-composition elements that resemble the values of Social Economy, which makes us think that the combination of both systems will generate a modernized enterprise system, human, according to social and able to offer alternatives that promote social welfare demands.

Keywords: Social economy, Alternative methods of conflict resolution, Human capital, Social responsibility, Corporate welfare.

Resumo

A economia social surge em resposta à necessidade de transformar o sistema econômico tradicional incorporando a concepção social. Reconhece o indivíduo $\mathrm{e}$ motiva suas interações para favorecer seu desenvolvimento pessoal e profissional. Essas interações com grupos, seções, equipes ou sociedades provavelmente levarão a situações de conflito que exigem respostas de acordo com a filosofia da entidade, uma filosofia que, no caso das empresas da economia social, deve estar alinhada com seus valores de auto-realização, solidariedade, igualdade, compartilhamento de responsabilidades e responsabilidade. Os Métodos Alternativos de Solução de Conflitos favorecem a autodeterminação, buscam a igualdade de poder e a auto-composição, elementos que se assemelham aos valores da economia social, o que nos faz pensar que a combinação de ambos os sistemas gerará um sistema de negócios modernizado, humano, de acordo com as demandas sociais e capaz de oferecer alternativas que favoreçam o bem-estar social.

Palavras-chave: Economia social, Métodos alternativos de solução de conflitos, Capital humano, Responsabilidade social, Bem-estar empresarial..

Cómo referenciar este artículo: Palmer, J. \& Iglesias, E. (2017). La gestión positiva del conflicto en la economía social. Los MASC como vía generadora de bienestar empresarial. Pensamiento Americano, 10(19), 23-42. http://dx.doi.org/10.21803\%2Fpenamer.10.19.462

Recibido: Octubre 15 de 2016 • Aceptado: Febrero 3 de 2017

* Los beneficios de la mediación comunitaria en el proceso del desarrollo local.

1. Licenciado en Geografía. Maestría en Gestión de Empresas de Economía Social por la Universidad de Mondragón, País Vasco, España. Estudiante de Doctorado en Métodos Alternos de Solución de Conflictos en la Facultad de Derecho y Criminología de la UANL, México. jorgepalmer@gmail.com

2. Trabajadora Social. Maestría en Mediación. Doctora en Intervención Social y Mediación por la Universidad de Murcia, España. Profesora-Investigadora Tiempo Completo Tipo A en la Facultad de Trabajo Social y Desarrollo Humano en la UANL, Mexico. Nivel 1 Sistema Nacional de Investigadores de México. eiglesiasortuno@gmail.com 


\section{Introducción}

La Economía Social (en adelante ES) es un espacio académico que en los últimos años ha ganado peso en el ámbito de la investigación y en el espacio de la gestión eficaz empresarial. Este trabajo se enmarca dentro de este espacio, por lo que consideramos necesario iniciar con un contexto teórico que enmarque el sentido y significado de la economía social, así como nos sitúe en sus principales contextos teóricos.

Como introduce Coraggio (2003, p.2) la economía, en su expresión más profunda y amplia, es el sistema que se da una comunidad o una sociedad de comunidades e individuos, para definir, generar y administrar recursos a fin de determinar y satisfacer las necesidades legítimas de todos sus miembros. A este respecto, añade Baquero (2003, p.51) que la vida económica está profundamente vinculada a la vida social, y no puede ser entendida al margen de sus costumbres, moral y hábitos de sociedad en la cual se desarrolla su actividad, no puede estar desvinculada de la cultura.

Indica Rojas (2009) que a mediados de los años 50 del siglo pasado se instaura un dominio creciente de la significación capitalista dando como resultado un cambio en la sociedad que se ve acompañado de una crisis. Para resolverlo es necesario que la sociedad tome nuevamente como eje central el trabajo productivo en el contexto de una cultura inclusiva que contemple la gerencia androcrática en el manejo de las empresas e instituciones. Afirma Lisboa (2001), que los movimientos sociales y políticos exigen que la sociedad ejerza el control sobre la riqueza producida y la construcción de mercados éticos. Este cambio, en palabras de Sanchís y Campos (2008, pp.187-188) tiene por objeto la introducción de cambios relacionados con nuevas formas organizativas y de gestión dentro de la organización. Se puede decir, que las empresas de economía social surgen, en gran medida, como resultado de una innovación social, ya que significan nuevas formas de organización del trabajo basadas en el establecimiento de fuertes relaciones sociales tanto con sus clientes como con sus trabajadores.

Indica Coraggio (2011, pp.163-167) que convocadas por la consigna de que otra economía es posible, concurren múltiples variantes como la economía social, la economía solidaria y muchas otras propuestas que pretenden encarnar concepciones teórico-ideológicas de la buena sociedad. Todas estas variantes suponen redefinir las relaciones hoy predominantes entre economía y sociedad limitando el automatismo del mercado, haciendo operar el principio de redistribución, promoviendo formas económicas que generan o están asociadas con otros valores y otra calidad de lazos sociales.

La economía solidaria, como afirma Mance (2001), abarca diversas prácticas que defienden la participación colectiva, autogestión, democracia, igualitarismo, cooperación, autosustentación, promoción del desarrollo humano, responsabilidad y preservación de los ecosistemas. Añade Singer (2003, p.209) que el surgimiento 
de la economía solidaria significa el regreso a los principios, la valorización de la democracia y de la igualdad en el campo de la producción, distribución y la intermediación financiera. Coincide Lechat (2003), en que producir y trabajar de una forma solidaria y autogestionada sería volver al principio fundamental de las relaciones humanas. Al respecto afirman Levresque, Bourques y Forgues (2001), que la economía social es una forma de alejamiento, un regreso a la autenticidad de la acción solidaria. Las empresas que se erigen sobre la filosofía de la economía social o solidaria adquieren las principales características de esta nueva concepción económica. Las empresas de la Economía Social y Solidaria (en adelante ESS), en palabras de Sanchís y Campos (2008, p.188), han destacado tradicionalmente por sus orígenes y por los principios y valores que definen su filosofía, en la aplicación de la innovación social $y$ en la actualidad se enfrentan a retos que las obligan a desarrollar nuevos sistemas de innovación social para seguir diferenciándose del resto de empresas denominadas capitales.

La economía moral es definida por Lechat (2003, p.165), como una economía que se basa en ciertos valores como la justicia social, la solidaridad y el respeto por la naturaleza; busca la socialización de la riqueza privilegiando las necesidades sociales sobre el lucro de los monopolios, el valor de uso sobre el valor de cambio. Para ello, es necesario un proceso de reformulación de la concepción tradicional de la economía y la incorporación de procedimien- tos de gestión novedosos. Coraggio (2003, p.4) presenta una propuesta que puede favorecer el desarrollo de la economía moral gestionando socialmente los recursos y las necesidades, y regulando los mecanismos para su resolución, para conseguir esto es necesario trabajar sobre la compleja y multivariada relación necesidad-satisfactor como un problema no meramente instrumental, sino sociocultural y políticamente estratégico

El capital social, en palabras de Baquero (2003, p.52), es diferente a otros tipos de capital humano, ya que es transmitido por mecanismos culturales, tales como: religión, tradición, hábito histórico, costumbre y sobrevivencia. La adquisición de capital social requiere que las personas acepten y valoricen las normas éticas y morales de la comunidad y, en este proceso, adquieran virtudes cívicas como la lealtad, honestidad y confiabilidad. Cuesta (2004, p.46) define el capital social como el conjunto de recursos (tangibles o virtuales) acumulados a través de las relaciones sociales externas e internas por la organización y por sus participantes. Al respecto firmaba Putnam (1993), el capital social favorece una mejor cooperación y coordinación en las organizaciones sociales al potenciar los valores compartidos, la comunicación, la comprensión mutua y la reputación de la entidad, idea que reafirma posteriormente Baquero (2003, p.53), cuando indica que el capital social surge como un bien público capaz de generar un nuevo contrato social anclado en la cooperación recíproca, solidaria y colectiva. 
El concepto de innovación social-empresarial se conecta directamente con otros conceptos de gran actualidad como la Responsabilidad Social Corporativa (en adelante RSC). La RSC se puede definir, como proponen Cuesta y Valor (2003, p.7) como el conjunto de obligaciones y compromisos, legales y éticos, nacionales e internacionales, con los grupos de interés, que se derivan de los impactos que la actividad y operaciones de las organizaciones producen en el ámbito social, laboral, medioambiental y de los derechos humanos. Por lo tanto la RSC afecta a la propia gestión de las organizaciones, tanto en sus actividades productivas comerciales como en sus relaciones con los grupos de interés. Estos grupos de interés son los denominados stakeholders, definidos por Freeman (1984) o Lozano (1999) como los grupos o individuos que afectan o son afectados en la actividad empresarial que ejecutan cierto poder en las relaciones que se originan en el desarrollo empresarial. La RSC nos presenta una estrategia empresarial que otorga gran relevancia a sus componentes o stakeholders y concibe a estos grupos como motores de la producción y el impacto de la empresa en la sociedad.

Para concluir la introducción de este estudio, recurrimos a las palabras de Coraggio (2003, p.18) cuando afirma que el sistema empresarial seguirá sufriendo una insuficiencia dinámica para reintegrar a una gran parte de los trabajadores que expulsó, y no podemos esperar que con un impulso del mercado interno vayamos a cambiar las tendencias que marca el nuevo paradigma tecnológico. La reactivación de la producción empresarial para el mercado interno de la exportación es fundamental, pero es preciso a la vez construir nuevas estructuras de producción, con otras relaciones sociales, orientadas por la reproducción ampliada de la vida de todos. Es en este aspecto donde podemos concebir la incorporación de los MASC a las estructuras relacionales y operativas en las empresas, para aportar esa esencia innovadora, transformadora, positiva, dinámica y acorde a los intereses, necesidades e iniciativas de quienes conviven en ese entorno para el desarrollo interno empresarial y su proyección a las relaciones externas con otras empresas o con el entorno social. Esta ESS mostrará rápidos resultados, capacidad para autosustentarse, reducir el desempleo y resolver una parte significativa de las necesidades de los trabajadores y sus familias, manteniendo otras relaciones, valores y motivaciones.

\section{Economía Social}

El trabajo que presentamos tiene como objeto principal de estudio la Economía Social (en adelante ES), respuesta de la sociedad moderna a las carencias del modelo tradicional económico. Monzón y Defourny (1992) afirman que la actividad de las empresas que participan de esa economía se centra en llevar a cabo proyectos colectivos, que no ocupan interés para las empresas capitalistas y no son atendidos por las administraciones públicas, con el fin de construir una alternativa empresarial denominándose comúnmente como Tercer Sector de Acción Social (TSAS), Bastidas-Delgado y Richer (2001, p.6), indican que 
a pesar de que las organizaciones que forman parte del tercer sector son anteriores, es recientemente, debido al contexto actual de crisis y de redefinición de las relaciones entre el Estado y la sociedad civil, cuando se enfatizan las potencialidades de la participación de la sociedad civil para la solución de los problemas sociales y la construcción de una sociedad más democrática. Por estas fechas, la noticia del inicio de negociaciones entre el Gobierno de Colombia y las FARC suponen un tema de interés social y político de carácter internacional. A colación de este trabajo de investigación es importante destacar que la Reforma Rural Integral es el primer punto de los acuerdos entre Colombia y las FARC, siendo la economía social y solidaria la base para establecer acciones al respecto ${ }^{1}$. Este es el ejemplo evidente de la humanización y resocialización de la economía y la prueba del impacto social que ejerce este nuevo sistema económico de índole social.

\section{Aproximación al concepto}

Para comprender las características de la ES hemos de realizar un análisis de las principales definiciones existentes sobre este tema. Como primer documento de estudio, abordamos la definición del Conseil de Walton de l'Economie Sociale (1990), que define la ES como el fragmento de la economía integrada por organizaciones privadas que comparte entre sí cuatro características: finalidad de servicio a

1 El Salmón Contracorriente. http://elsalmoncontracorriente. es/?El-acuerdo-de-Paz-en-Colombia

La Coperacha. http://www.lacoperacha.org.mx/AcuerdosPaz-Colombia-FARC-incluye-cooperativas-economia-social-solidaria.php sus miembros o a la colectividad; autonomía de gestión; procesos democráticos y primacía de las personas y del trabajo sobre el reparto de rentas. Al respecto añaden Levesque y Mendell (1999) que toda economía es social en la medida en que no puede funcionar sin instituciones, sin el compromiso de las personas o sin el apoyo de las comunidades así como del Estado. La ES reconoce las dimensiones sociales de la economía al referir organizaciones basadas en la democracia y el empresariado colectivo. Bastidas-Delgado y Richer (2001, p.5) indican que la economía social es un sector de la economía formado por las organizaciones cuya especificidad es la de combinar dos estructuras: una asociación de personas y una empresa cuya producción está destinada a satisfacer las necesidades del grupo de personas que son sus propietarias. En este sentido, deducimos de las diversas aportaciones en la obra de Laville y Nyssen (2001) que la economía social tiene el objetivo de corregir los efectos sociales de la difusión del mercado, de conciliar interés y justicia.

\section{Las entidades de economía social, rasgos} característicos

Las entidades de economía social son, en palabras de Monzón y Defourny (1992) entidades jurídicas que desarrollan sus actividades económicas y empresariales desde el ámbito privado y persiguen, bien el interés colectivo de sus integrantes, bien el interés general económico o social, o ambos, de conformidad siempre con los principios que orientan las prácticas de economía social y solidaria. Añade Navarro 
(1996, p.7) que la realidad social de las empresas de economía social es compleja, dinámica, sistémica y relacional. Es compleja debido a su capacidad para generar nuevas relaciones económicas y diferentes respuestas a problemáticas de sus socios y su comunidad a través de sus propias redes donde, al estar fuertemente asociados entre sí, aportan una gran capacidad de adaptación y actuación como agentes autónomos para influir sobre los demás, dotándolas de dinamismo y resiliencia, requiriendo obligatoriamente una aproximación a su estudio desde el enfoque cualitativo. Las empresas de economía social cumplen una función de cambio sistémico y relacional, buscan a través del interés en la comunidad, la intercooperación, la solidaridad y la participación activa, generar nuevas relaciones público-privadas para dar solución a alguna necesidad social, abarcando funciones que quedan fuera de las actividades propias de la administración pública y de las relacionadas con la economía tradicional de mercado.

En este sentido incorpora Wautier (2003, p.187), que la ES es un conjunto de organizaciones y empresas cuyas actividades productivas responden a principios prioritarios: adhesión libre, democracia interna, ganancia limitada, respeto a la dimensión humana de la actividad y solidaridad. La ES se traduce como un prisma desde el que enfocar un nuevo modelo empresarial que se ha extendido a nivel mundial, siendo ejemplo de ello las diferentes definiciones, recomendaciones y experiencias en diferentes países. Un ejemplo de ello es la aportación del Comité Económico y Social Europeo que identifica la aportación de Chaves y Monzón (2006) para generar la siguiente definición de Empresa de Economía Social de aplicación en todo el territorio europeo:

Conjunto de empresas privadas organizadas formalmente, con autonomía de decisión y libertad de adhesión, creadas para satisfacer las necesidades de sus socios a través del mercado, produciendo bienes y servicios, asegurando o financiando y en las que la eventual distribución de beneficios o excedentes entre los socios así como la toma de decisiones, no están ligados directamente con el capital o cotizaciones aportados por cada socio, correspondiendo un voto a cada uno de ellos. La economía social también agrupa a aquellas entidades privadas organizadas formalmente con autonomía de decisión y libertad de adhesión que producen servicios de no mercado a favor de familias cuyos excedentes, si los hubiera, no pueden ser apropiados por los agentes económicos que las crean, controlan o financian.

Como deducimos de las aportaciones estudiadas, la ES nos presenta un sistema empresarial materializado en empresas donde rige la idea transversal de libertad de decisión, democracia participativa, optimización de recursos, respeto a los Derechos Humanos y Solidaridad. Para ello, se pone el punto de interés en los diferentes sistemas que componen el organismo empresarial que ejercen poder en él para garantizar el bienestar, las relaciones positivas y la optimización del capital humano. Monzón 
(2006, p.22), incluye a esta reflexión que desde la filosofía de la economía social, las organizaciones tienen como objetivo principal el servicio a las personas o a otras organizaciones de ES.

La ES sitúa en el centro de sus preocupaciones a los seres humanos que constituyen su razón de ser, la finalidad de sus actividades. En este sentido afirman Gonzalez y Coquies (2011) que la idiosincrasia de las empresas de economía social sitúan a la persona en el centro de la actividad del negocio, siendo el objetivo principal la satisfacción de sus necesidades. Esta circunstancia obliga a tener en cuenta las realidades de cada individuo y ejercer de forma diferente ante cada situación. Palacios y Climent (2008) detallan las características de la persona en las empresas de ES afirmando que poseen el triple rol y que esto es el principal cambio de perspectiva a la hora de afrontar las relaciones personales que se dan en este tipo de organizaciones respecto a las formas jurídicas de la economía tradicional. Siguiendo los principios de participación democrática y distribución de resultados en función del trabajo, las personas que adquieren el rol de propietarios del negocio como socias y disfrutan al mismo tiempo de la condición de trabajadores. Las personas socias que desarrollan la actividad de estas entidades también adquieren la condición de consumidores o clientes ya que reciben bienes o servicios en contraprestación de su desarrollo laboral y en calidad de parte integrante, bien como vecinos o como usuarios de la comunidad en la que actúa la empresa.

\section{Principios rectores de la economía social}

La ES posee principios rectores que caracterizan y determinan su filosofía. Estos principios clarifican el sentido de esta nueva corriente y evidencia sus diferencias con el modelo empresarial tradicional. En España, la Ley 5/2011, de 29 de mayo, de Economía Social recoge los siguientes principios esenciales de la ES:

- Importancia de las personas y del fin social sobre el capital, generando trabajo digno y emancipador, desarrollando una gestión autónoma y transparente, democrática $y$ participativa.

- Aplicación y distribución de los resultados obtenidos en función del trabajo realizado por sus socios al fin social objeto de la entidad, generando autofinanciación sustentable, favoreciendo la igualdad de oportunidades entre hombres y mujeres, protegiendo la durabilidad del empleo y relegando el papel del capital a una herramienta puramente práctica en tanto no se considera como objetivo en sí mismo.

- Promoción de la solidaridad interna y con la sociedad.

- Independencia respecto a los poderes públicos, el acceso de los trabajadores a todas las formas de conocimiento y a los medios de producción.

- Producción socialmente responsable, la autogestión y la reciprocidad colaborativa, afianzando el desarrollo territorial favoreciendo la cohesión social frente a la deslocalización y dinamizando las relaciones económicas locales y regionales mediante 
el mejor aprovechamiento de los recursos endógenos.

Los valores y principios éticos y sociales hacen que las relaciones que se generan dentro de estas empresas de economía social adquieran un carácter afectivo e identitario, dotando a estas relaciones de una perspectiva humanista que conlleva unas relaciones que han de tener en cuenta las necesidades y condiciones personales para dar un buen servicio individual que produzca a su vez beneficios colectivos (Laville $\&$ Nyssens, 2001). Deducimos pues que la estructura social propia de cada entidad se compone de sus creencias, valores y mecanismos de acción que configuran su marco filosófico o ideológico y que otorga al conjunto una cultura operativa que determina su realidad y sus interacciones. Siendo pues el marco ideológico de la ES un esquema integrador, capacitador, promotor de la capacidad humana, protector $\mathrm{y}$ responsable que ofrece estrategias y procedimientos generadores de bienestar social interno y externo.

\section{Conflicto en empresas de economía social}

Apunta Loaiza (2011, p.18) que la organización es un sistema que se ve afectado por el entorno y por todos aquellos elementos que interactúan con ella, se debe entender que el hombre, como sistema individual, desempeña un papel fundamental en el éxito o fracaso de la organización. Respecto a los conflictos en las empresas de ES, afirman Fernández y Sanjuán (2012) que las relaciones que se producen al desarrollar cualquier actividad económica in- fluyen directa e indirectamente en varios grupos de personas. Hecho relacional que afecta a la hora de gestionar los posibles conflictos que se pueden dar en las empresas, sean sociales o no. Los conflictos que surgen en una empresa de economía social pueden clasificarse así en internos y externos. Así pues, podemos decir que el conflicto está presente en las organizaciones laborales propias de la ES.

Le ES se caracteriza por poseer una filosofía transversal donde los procesos democráticos, la toma de decisiones compartida, los procedimientos asamblearios y el reconocimiento de las capacidades y autodeterminación de las partes caracterizan los procedimientos de funcionamiento interno y su proyección externa. Estos mecanismos propios suponen la interacción constante entre los miembros de la organización, escenario donde es habitual la aparición de conflictos de diversa índole. Por esto, se precisa un modelo que conciba el conflicto como oportunidad, como fuente de cambio, renovación y posibilidades de mejora para el conjunto organizativo. Según las aportaciones de Peña (2007) y Ortuño (2003), deberíamos emplear otros medios alternativos de resolución de conflictos que garanticen la salvaguarda de las relaciones institucionales.

\section{Concepción del conflicto y sus componen-} tes

Touzard (1980) define el conflicto como una situación en la cual unos actores (individuos, grupos, organizaciones o naciones) persiguen objetivos opuestos, o buscan simultanea 
y competitivamente el mismo objetivo. Al respecto, Rubin, Pruitt y Hee (1994) indican que el conflicto es la diferencia de intereses percibida o una creencia que desarrollan las partes, en sus aspiraciones normales, de que no pueden alcanzar simultáneamente sus objetivos. Los conflictos son situaciones en las que dos o más personas entran en oposición o desacuerdo porque sus posiciones, intereses, necesidades, deseos o valores son incompatibles, o son percibidos como incompatibles, donde juegan un papel muy importante las emociones y sentimientos y donde la relación entre las partes en conflicto puede salir robustecida o deteriorada en función de cómo sea el proceso de resolución del conflicto (Torrego, 2003).

Como indica Vinyamata (1999), los conflictos son el motor y la expresión de las relaciones entre las personas, y los constantes y repetidos intentos por reprimirlos, contenerlos o eliminarlos, no hacen más que incrementarlos, desarrollarlos y multiplicarlos. De las aportaciones de los autores, podemos extraer que el conflicto es una situación que afecta a todo tipo de relación social basada en una oposición (real o construida). Estas situaciones de conflicto no deben ser reprimidas, deben ser enfrentadas desde un prisma de oportunidad y entendimiento para así crear un escenario donde resulta de gran relevancia el estudio de los intereses y objetivos de los implicados para así poder obtener una resolución eficaz. Añaden al respecto Iglesias, Palmer y Perona (2016, p.125) que la aparición de conflictos en el entorno de trabajo, surgidos de las relaciones entre los miembros de una empresa, supone un ámbito de gran interés puesto que las situaciones de conflicto que no sean resueltas de modo efectivo pueden suponer un perjuicio para la entidad.

La resolución eficaz del conflicto precisa un entendimiento entre las partes basado en una relación de igualdad y colaboración, rasgos característicos de la filosofía ganar-ganar que atribuye capacidad a ambas partes para conseguir una solución igualmente satisfactoria para ambas. En este sentido afirma Covey (2002, p.264), que la estrategia de ganar-ganar se materializa en acuerdos que clarifican y administran efectivamente tanto las expectativas como el éxito y esta filosofía precisa organizaciones que la apoyen para generar verdadero impacto social. Esta filosofía del ganar-ganar se convierte en un elemento más de las características que definen e identifican la estructura y personalidad de una organización que aglutina los elementos propios de la ES y de la perspectiva positiva y constructiva de los conflictos.

\section{El conflicto empresarial a nivel interno}

Como afirman Constantino y Merchant (1997, p.32), las organizaciones y los individuos que cumplen una función determinada y forman parte de grupos dentro de esas organizaciones, viven conflictos en la interacción con fuerzas tanto externas como internas. Incorpora Agudo (2006, p.32), que tanto entre las personas como en las organizaciones existen cotidiana y permanentemente conflictos diversos y ello afecta a todo tipo de personas como 
de organizaciones. Añaden las autoras que en el contexto de la organización, el conflicto es una expresión de insatisfacción o desacuerdo con una interacción, un procedimiento, un producto o un servicio. Es un proceso y no un producto. En la organización es en realidad un indicador de insatisfacción en ella, es un problema tangible que puede resolverse, ser domesticado, manejado o controlado. El conflicto es el proceso de expresar insatisfacción, desacuerdo o expectativas no cumplidas en cualquier intercambio dentro de una organización (Constantino \& Merchant, 1997 p.34).

Afirma Femenia (2014) que en todos los grupos sociales, al interactuar personas diferentes, el conflicto aparece de forma inherente. Además del impacto económico, los conflictos suponen un impacto emocional que genera costos directos e indirectos en las organizaciones e influyen en el correcto desarrollo de estas. Al respecto añade Gezuraga (2014) que dentro de las empresas de economía social no hay excepción a esta realidad, convirtiéndose esta conflictología específica en objeto de estudio para investigaciones de diferentes índoles y disciplinas. Para las empresas de economía social, sus principios y valores en general, y la gestión democrática y la igualdad de socios en particular son fuente primaria de divergencia.

Constantino y Merchant (1997, pp.33-35), afirman que cierta persona o grupo no está contento con otra persona o grupo o con alguna cosa y esa insatisfacción puede ser resultado de diferentes situaciones que generen conflictos, las autoras proponen las siguientes:

\section{Expectativas divergentes}

A partir de la propuesta de las autoras, lo entendemos como una situación problemática que surge al no alcanzar las expectativas que se había supuesto o diseñado anteriormente. Puede aplicar a nivel individual, pero también a nivel grupal o institucional. Al respecto, afirma Galtung (2003) nos indica que las necesidades humanas básicas precisan ser atendidas y, en el caso de que se dificulte esto, se generan situaciones de conflicto en los diferentes niveles de necesidad que determina Maslow (1991).

\section{Objetivos contradictorios}

Lo entendemos como la situación en la que los objetivos marcados entran en contraposición con otros, bien sea propios del individuo, del grupo o sistema. Se agudiza la situación cuando la escasez de recursos convierte los objetivos en excluyentes. En este sentido, sostiene Lederach (2000) que la idea de que la disposición, real o percibida, de objetivos incompatibles o no viables es motivo de generación de conflicto.

\section{Intereses en conflicto}

Lo interpretamos de manera similar al conflicto derivado de objetivos contradictorios. Se agudiza la situación cuando los intereses son contrapuestos o percibidos como tal. Manifiesta Lederach (2000) que en este caso, el conflicto se basa en incompatibilidades en la consecución de intereses aparentemente opuestos, para 
lo que se hace preciso trabajar el entendimiento, la legitimación y la tolerancia.

\section{Comunicaciones confusas}

La comunicación es la clave para el entendimiento y el diálogo eficaz, una mala comunicación genera obstáculos que impiden a las personas estar informadas y favorece los malos entendidos y la generación de problemas en el entorno y el desempeño. Si incorporamos la perspectiva de Lederach (2000), el autor declara que la comunicación es causa de problemas en la relación y genera el conflicto que determina como innecesario.

\section{Relaciones interpersonales no satisfactorias}

En este sentido, podemos interpretar que, motivos de diferente índole, pueden generar situaciones de desconfianza, hostilidad, sospecha y juicios erróneos sobre la actitud de la otra persona, hecho que dificulta el proceso productivo y el desempeño de las funciones propias. Redorta (2007) califica esto como aspectos negativos de una situación de conflicto, sin embargo sostiene que un procedimiento adecuado de gestión, puede reducir incluso eliminarse estos aspectos negativos.

\section{Como apuntan Constantino y Sickles} (1997, p.31) las organizaciones están plenas de conflictos que adoptan muchas formas y tienen muchas caras. Pueden ocultarlos, aplastarlos, controlarlos, luchar contra ellos, negarlos o evitarlos, pero hagan lo que hagan, no pueden hacerlos desaparecer: el conflicto es parte de la vida de las organizaciones. Ramos (2006, pp.109-110) indica que los conflictos tienen importantes efectos negativos para la organización:

- Creencia de que la solución al conflicto es cuestión de fuerza.

- La comunicación es disfuncional y prima la actitud hostil.

- Se producen juicios, valoraciones y suposiciones basadas en interpretaciones propias que nos conducen a juicios erróneos.

- Se produce una descontrolada escalada del conflicto, donde los implicados se polarizan, se perciben como oponentes y tratan de ganar al hacer perder al otro.

Como hemos estudiado anteriormente, el conflicto tiene una acepción positiva que defiende la idea de poder resolver de forma eficaz la situación y de esta forma extraer consecuencias positivas para los implicados y al entorno en el que se produjo. A este respecto añade Ramos (2006, p.110) que el conflicto en la empresa, bien gestionado es motor de cambio social y personal, fomenta la identidad y el sentimiento de pertenencia, establece canales y estilos de comunicación duraderos y fomenta la capacidad y confianza de las partes implicadas. Es necesario para las organizaciones instaurar la concepción positiva del conflicto pues es la clave para gestionarlos adecuadamente. Esto podemos conseguirlo mediante la inclusión de los métodos alternos de solución de conflictos, cuyo principio es la concepción del conflicto como oportunidad de cambio positivo. 
Estos aspectos estudiados muestran que las interacciones entre los diferentes miembros de una organización empresarial son susceptibles de generar situaciones que pudieran derivar en conflicto, por ejemplo intereses contrapuestos, patrones de comunicación ineficaces, expectativas truncadas, incluso dificultades para la consecución de los objetivos personales o grupales. Estas situaciones suponen un riesgo para el conjunto empresarial puesto que, una gestión negativa, puede afectar en la producción y funcionamiento del sistema, hecho que afecta directamente a la competitividad empresarial, la imagen corporativa y el bienestar interno y externo del organismo.

La gestión del conflicto en entidades empresariales

Es un proceso comunicacional que tiene por objetivo cambiar los estados emocionales negativos del conflicto por otros que permitan promover una solución al mismo. La definición de Cascón (2002) introduce otro elemento esencial, el de la diferenciación terminológica entre resolución, manejo y gestión de conflictos y mantiene al respecto que resolver conflictos, a diferencia de manejarlos o gestionarlos, se entiende por el proceso que nos lleva a abordarlos hasta llegar a descubrir y resolver las causas profundas que lo originan. A esta idea añade García-Longoria y Serrano (2002, p.231) que la resolución de conflictos como el proceso orientado a manejarlos y a negociar una solución.

Cuando hablamos del estilo de enfrenta- miento a un conflicto, estamos hablando del conjunto de acciones o comportamientos que va a desarrollar una persona o entidad que se ve involucrada en un conflicto para tratar de gestionarlo. Hemos de partir de la base de que cada persona o grupo es diferente, cada persona siente y padece de manera diferente un conflicto $\mathrm{y}$, lo más importante, cada persona espera conseguir resultados diferentes a la hora de gestionar un conflicto. Cada sistema va a actuar de forma diferente, con un estilo diferente, pero siempre dentro de la clasificación que de ellos hacen autores como: Lederach (2000); Torrego (2003) que proponen cinco estilos de enfrentamiento al conflicto.

- Competición: Perseguir los objetivos personales a costa de los otros, sin detenerse a pensar en los demás.

- Cooperación: Implica la búsqueda de un objetivo común mediante la colaboración de las partes en conflicto, para obtener los mejores resultados para las partes.

- Evasión: Debido a la concepción negativa que se tiene sobre el conflicto, la persona prefiere evitarlo o posponerlo, lo cual implica que no obtiene una solución.

- Sumisión: Supone ceder habitualmente a los puntos de vista del otro, a costa de no obtener satisfacción propia.

- Compromiso: es una actitud basada en la negociación, basada en la búsqueda de soluciones y al pacto entre las partes. La solución satisface parcialmente a las dos partes.

A partir de las aportaciones de los autores podemos concluir que, los estilos de gestión 
del conflicto tienen aplicabilidad a nivel individual, grupal o institucional y que, como se deriva de su estudio, cada uno de ellos posee unas características, una visión, un posicionamiento y un objetivo cuando se enfrenta a una situación de conflicto. Desde la perspectiva individual y, teniendo en cuenta los diferentes estilos analizados, destacamos la aportación de Constantino y Sickles (1997, p.43), cuando afirman que los individuos que tienen funciones y forman parte de grupos dentro de las organizaciones, dan respuestas de confrontación o evasión frente al conflicto. Esta respuesta puede ser reflejo de la que ofrece la organización o puede ser diferente. Así mismo, las autoras hacen una reflexión acerca de los diferentes estilos grupales de gestión del conflicto y afirmando que las respuestas de las organizaciones al conflicto son específicas de cada situación o contexto y también dependen del individuo. Las organizaciones con una mentalidad guerrera quieren ganar a toda costa y genera estrategias que permitan alcanzar la meta principal que es controlar el conflicto. Por otro lado, las empresas con mentalidad escape tienden a diseñar estrategias para evitar el conflicto y retrasar su abordaje. Las empresas caracterizadas por poseer una identidad arrogante o depredadora poseen unos estilos de afrontamiento de las situaciones de conflicto que se caracterizan por la arrogancia, o la actitud de batalla. Por otro lado, las empresas que se caracterizan por una identidad de escape o evasión, tienen unos estilos de afrontamiento al conflicto basados en la negación, la evitación o la adaptación (Constantino \& Sickles ,1997 pp.37-40).
De esto extraemos que es importante identificar el estilo de gestión de la empresa, pues nos brindará información acerca de los valores internos, la estructura y filosofía según su forma de actuar y también nos permitirá prever las consecuencias o posibles resultados en las situaciones de conflicto. Además, podemos concluir que la posición ante el conflicto que más conviene a la institución empresarial es la posición colaboradora, donde las partes se consideran capaces, iguales, colaboradores y necesarios y donde la filosofía del acuerdo, entendimiento y diálogo es una realidad. Este procedimiento de gestión de conflictos puede incorporarse a la empresa si, como así determinan los autores estudiados, forma parte del sentir empresarial y de la filosofía de la entidad.

La ES nos habla de un sentido empresarial basado en la participación democrática, la capacidad, el reconocimiento y la harmonía, elementos que pueden hacernos pensar que este tipo de empresa precisa un método de gestión basado en estos mismos elementos que, como hemos estudiado, genere situaciones positivas, enfrente el conflicto desde la colaboración y apueste por mecanismos autocompositivos que permitan el entendimiento y la satisfacción de los implicados.

Los MASC para la gestión del conflicto empresarial

El conflicto surge en las empresas de forma interna entre sus diferentes componentes (trabajadores, gestores, coordinadores, proveedores, etc.) y obtener una solución óptima se 
ha convertido en un área de importancia para la empresa, para lo que es habitual recurrir a métodos especializados de resolución de conflictos. El sistema jurídico se ha erigido como el método tradicional de gestión de conflictos, donde un sistema externo actúa como autoridad conocedora y competente para evaluar, juzgar y determinar una solución al conflicto acorde a lo establecido en los códigos legales relacionados con la materia. Al respecto $\mathrm{Fe}$ menia (2015), indica que las empresas de ES han recurrido al sistema judicial como método para la gestión de los conflictos debido sobre todo a la ausencia de otras referencias o modelos más adecuados. Añade Agudo (2006, p.32) que nuestra cultura jurídica y social nos hace desconfiar de soluciones o alternativas distintas a las ya consagradas, que en materia de conflictos son las basadas en el poder y el derecho con sistemas públicos judiciales y administrativos basados en la autoridad y la ley.

Los métodos de resolución de conflictos son diversos, siendo el sistema judicial el método tradicional a pesar de sus flaquezas, indica Vázquez (2007), que la judicialización de los conflictos supone una llegada masiva de los ciudadanos a la Administración de Justicia por mínima que sea la disputa. Esto hace necesario la implementación de métodos alternativos más eficaces y ajustados a las necesidades de la población. Una resolución pacífica del conflicto dependerá del empleo de un método gestor que permita el análisis, comprensión y complementación de las necesidades, intereses y propuestas de las partes implicadas en él. Podemos decir, por tanto, que la resolución de los conflictos está vinculada al proceso de gestión que sea desarrollado por los actores implicados. $\mathrm{Al}$ respecto, afirman Munduate y Medina (2005, p.51) que la gestión del conflicto puede hacer referencia a diferentes procesos e intervenciones con la finalidad de reducir, potenciar o resolver una situación de intereses o preferencias divergentes entre dos o más partes pertinentes.

Si tenemos en cuenta las aportaciones de Alzate (2007, p.41) para romper el patrón que nos mantiene en el conflicto y para resolverlo de una manera productiva, primero necesitamos tomar conciencia de las creencias y respuestas que perpetúan nuestra conducta negativa. La reflexión es un paso vital para lograr esta toma de conciencia. Podemos dar un paso hacia delante en el conocimiento de nosotros mismos y de nuestras opciones, sabiendo que, aunque el conflicto es inevitable, no tiene porque ser destructivo. Si atendemos a esta definición de conflicto, deducimos que la metodología de gestión que sigamos para la resolución de un conflicto va a determinar el resultado de este. Es por esto que, según las aportaciones de Peña (2007) y Ortuño (2003), deberíamos emplear otros medios alternativos de resolución de conflictos que garanticen la salvaguarda de las relaciones personales de los miembros del sistema familiar.

Indican Constantino y Sickles (1997, p.37) que las respuestas de las organizaciones al conflicto se dan de forma conjunta a la cultura de las organizaciones, a sus actitudes, valores, 
prácticas y creencias del sistema y sus miembros. Es decir, la cultura de la organización influye sobre las características de la respuesta que se otorga al conflicto. Estas aportaciones nos muestran un modelo de empresa donde los implicados son actores activos, donde las decisiones son compartidas y en el que las relaciones, la responsabilidad y la capacidad personal de los miembros son el elemento clave para su funcionamiento. Las empresas de ES tienen unos valores que basan los procedimientos de actuación empresarial hacia la consecución de oportunidades para los participantes, la consideración activa de las personas, la democracia, la negociación y la visión de oportunidad, por ello precisan unas estrategias acorde a esta filosofía

Los métodos alternativos, o en terminología inglesa ADR (Alternative Dispute Resolution), son procesos alternativos al sistema judicial. En estos métodos alternativos, más que la imposición de una solución, se devuelve a las partes el protagonismo perdido y su capacidad de razonamiento y decisión, y esto permite a las partes determinar su propia solución, (Ortuño, 2003). Como afirma el autor, aquellos problemas cuya naturaleza y complejidad permita su solución de una forma directa entre las partes deberían gestionarse empleando los ADR, dejando al sistema judicial los conflictos de mayor envergadura. Esto permitirá descongestionar la carga de trabajo en los juzgados, equilibrando su capacidad operativa a la demanda de la población y sobre todo garantizará una mayor calidad en su trabajo.
La Comisión Europea publicó en 2002 el Libro Verde sobre los ADR en el que se incluían los principios generales que todos los estados miembros de la Unión Europea que han sido consultados aceptan y sobre los que se desarrolla la actividad de las ADR, estos principios generales son los siguientes:

- La voluntariedad de las partes para someterse a los ADR se refiere a la libertad para dar por terminado el Proceso Judicial en cualquier momento, con la posibilidad de recuperar la tutela de sus derechos con carácter inmediato.

- La autonomía para organizar el procedimiento. Es uno de los principios más destacados, puesto que en cada caso y para cada ámbito de actuación se pueden pactar o fijar las reglas mínimas de actuación, con lo que las propias partes en controversia comienzan a construir las bases para resolver por sí mismas el conflicto.

- La exigencia de imparcialidad al tercero, junto con la neutralidad y la objetividad, son las condiciones indispensables establecidas en el Libro Verde que debe ofrecer el tercero mediador.

- La objetividad ha de entenderse como la ausencia de prejuicios subjetivos, cuya exigencia aquí es mayor que la que se reclama del tribunal en los litigios contenciosos, pues este tiene como referente la ley, mientras que el árbitro de equidad, el juez conciliador o el mediador no están vinculados por ninguna otra norma que la que las partes puedan establecer. Las partes deben percibir que el tercero considera legítimas sus 
respectivas opciones, que respeta las posiciones que muestran en la disputa y que les ayuda a encontrar la mejor solución posible para los intereses enfrentados, de tal forma que del acuerdo que se alcance no se genere la sensación de victoria ni de derrota para ninguna de ellas, sino la satisfacción de ambas por el problema resuelto.

- Se destaca especialmente la necesidad de respetar el principio de confidencialidad. Este es uno de los aspectos que según lo establecido en el Libro Verde, precisan de especial regulación, puesto que para buscar soluciones a los conflictos planteados se han de colocar las cartas sobre la mesa sin guardar bazas ocultas.

- La implantación de los sistemas alternativos se ha de enmarcar en el objetivo prioritario que es la recuperación del poder de las partes, facilitar el acceso a la justicia y a la obtención de una solución justa y eficaz en un plazo de tiempo razonable.

- La necesidad de garantizar el equilibrio real entre las partes. Este es un objetivo que presenta importantes dificultades por el carácter esencialmente consensual de los ADR. Las habilidades del tercero interviniente adquieren aquí una dimensión especial. Un acuerdo que haya sido suscrito por una de las partes por miedo, presión psicológica o por ausencia de la real comprensión de la trascendencia de su decisión, es esencialmente un acuerdo injusto.

Como concluimos del estudio de los MASC, representan una nueva perspectiva de la ges- tión de conflictos. Ofrecen una visión diferente al sistema jurídico tradicional, una nueva perspectiva que pone su interés en el bienestar de la persona y ofrece mecanismos capaces de dar respuesta a necesidades reales empleando para ello modelos inclusivos y garantes de los Derechos Humanos, la integridad y la capacidad de autogestión de las personas. Los MASC ofrecen una posibilidad real de acceso a un sistema de gestión de conflictos al reducir los costes económicos y genera un procedimiento más sencillo que favorece a la descarga de los Tribunales. Como punto de mayor relevancia, consideramos que los MASC devuelven el protagonismo a las partes, otorgándoles presencia, capacidad, protagonismo y reconocimiento durante el proceso de gestión de sus propios conflictos, de lo que se genera un agente activo en la sociedad y con interés por los procesos sociales en los que se ve inmerso.

\section{Discusión}

Los MASC surgen como un elemento renovador que tiene como objetivo romper con los estándares tradicionales de gestión del conflicto, con una intención de cambio social. En este sentido, al inicio de este estudio, mencionábamos que el objetivo de la ES era, igualmente, proporcionar un nuevo enfoque a la economía tradicional, con intención de humanizar los procesos mercantiles. Así pues, podemos deducir que, cada modelo en su propio ámbito, pero con una importante conexión: representan nuevas filosofías inclusivas, humanizadoras y de carácter social que pretenden generar cambios estructurales y sociales y que tienen como fin último el bienestar de las personas. 
Para comprender mejor la idea de combinar ambas esferas y con el objetivo de obtener un producto resultante de impacto social, incorporamos el siguiente cuadro en el que recogemos las principales ideas que sustentan cada área para así identificar los nexos de unión y su oportunidad para la estructura social.

Tabla 1. Comparativa entre valores de la ES y los MASC

\begin{tabular}{|l|l|}
\hline \multicolumn{1}{|c|}{$\begin{array}{c}\text { Valores de la } \\
\text { Economía Social }\end{array}$} & \multicolumn{1}{|c|}{ Valores de los MASC } \\
\hline $\begin{array}{l}\text { Autodesarrollo personal y y } \\
\text { grupal }\end{array}$ & $\begin{array}{l}\text { Autodeterminación y capa- } \\
\text { cidad }\end{array}$ \\
\hline $\begin{array}{l}\text { Desarrollo de la persona y su } \\
\text { autonomía }\end{array}$ & $\begin{array}{l}\text { Devolución de la capacidad } \\
\text { de decisión y acción }\end{array}$ \\
\hline $\begin{array}{l}\text { Derechos Humanos e integri- } \\
\text { dad de la persona }\end{array}$ & $\begin{array}{l}\text { Voluntariedad y confidencia- } \\
\text { lidad }\end{array}$ \\
\hline $\begin{array}{l}\text { Toma de decisiones conjunta, } \\
\text { no autoritaria }\end{array}$ & $\begin{array}{l}\text { Tercero imparcial y neutral, } \\
\text { no autoritario }\end{array}$ \\
\hline $\begin{array}{l}\text { Solidaridad e igualdad de } \\
\text { oportunidades }\end{array}$ & $\begin{array}{l}\text { Equilibrio e igualdad entre } \\
\text { partes }\end{array}$ \\
\hline $\begin{array}{l}\text { Responsabilidad social y co- } \\
\text { hesión social }\end{array}$ & $\begin{array}{l}\text { Solución satisfactoria según } \\
\text { intereses sociales para el } \\
\text { bienestar }\end{array}$ \\
\hline
\end{tabular}

Fuente: Elaboración propia

Observamos en este cuadro los principales valores que sustentan la Ecomonía Social y los Métodos Alternos de Solución de Controversias, donde observamos que, de manera coincidente, se promociona la participación y desarrollo del individuo, así como su autonomía; se protege a las personas mediante la confidencialidad del proceso, hecho que apoya $y$ garantiza los Derechos Humanos; se motiva la búsqueda de soluciones inclusivas, que satisfagan todos los intereses partiendo de una situación de equilibrio e igualdad entre las partes.
Además se percibe en ambas esferas la dimensión de impacto social desde la cohesión social, la responsabilidad y el bienestar. Observamos importantes nexos de unión entre los pilares fundamentales de ambas filosofías, hecho que hace pensar que la combinación de ambas ofrece un producto resultante motor de la economía y testigo del cambio social y la revalorización del capital humano y la justicia social.

Mencionábamos anteriormente en el inicio de este artículo que la economía tradicional está experimentando un cambio, una transformación, promovida por movimientos sociales que demandan incluir una perspectiva social a las dinámicas mercantiles. Este hecho origina el movimiento de la economía social, una economía que se caracteriza por la incorporación de la perspectiva social y humana, por el trato positivo hacia el individuo y por la ruptura con la autoridad propia de los mercados tradicionales, situando el foco en los mecanismos democráticos y participativos. Así pues, este cambio ha sido experimentado en otras esferas o cuestiones sociales, como es el caso de la justicia.

El sistema judicial ha manifestado importantes crisis de diversa índole: estructural, filosófica, operativa y funcional, surgiendo pues la corriente de los métodos alternos de solución de conflictos, los MASC. Así pues, los MASC y la Economía Social tienen en común que surgen como alternativas a elementos tradicionales y arraigados en la sociedad y en las interacciones sociales y que introducen importantes 
cambios que sitúan al individuo como foco de atención y que promueven la humanización y dignificación de las estructuras sociales modernas.

De esta manera, resulta interesante y pertinente el hecho de combinar, unir o mezclar estas dos alternativas para así poder crear un producto resultante que permita fortalecer el tejido social.

\section{Referencias bibliográficas}

Agudo Périz, J. L. (2006). Resolución alternativa de conflictos en las cooperativas. Acciones e Investigaciones Sociales, (22), 35-89.

Alzate Sáez de Heredia, R. (2007). La dinámica del conflicto. En H. Soleto \& M. Otero, Mediación y solución de conflictos. Habilidades para una necesidad emergente (pp. 37-49). Madrid: Tecnos.

Baquero, M. (2003). Capital Social. En A. D. Cattani (Coord.), La otra economía (pp. 51-58). Brasil: Fundación OSDE.

Bastidas-Delgado, O. \& Richer, M. (2001). Economía social y economía solidaria. Intento de definición. CAYAPA Revista Venezolana de Economía Social, (1), 1-27.

Cascón, P. (2002). Educar en y para el conflicto. Barcelona: Cátedra UNESCO sobre la paz y los derechos humanos.

Chaves, R. \& Monzón, J. L. (2006). La economía social en la Unión Europea. Comité Económico y Social Europeo: Mimeo.
Constantino C. A. \& Merchant, C. S. (1997). Diseño de sistemas para enfrentar conflictos. Una guía para crear organizaciones productivas y sanas. Buenos Aires: Granica.

Coraggio, J. L. (2003). Una alternativa socioeconómica necesaria: la economía social. Buenos Aires: Universidad Nacional General Sarmiento.

Coraggio, J. L. (2011). Economía Social y Solidaria, el trabajo antes que el capital. Quito: Ediciones Abya-Yala.

Covey, S. R. (2002). Los 7 hábitos de la gente altamente efectiva. Barcelona: Paidós Ibérica.

Cuesta González, M. (2004). El porqué de la responsabilidad social corporativa. ICE Boletín Económico, (2813), 45-58.

Cuesta González, M. \& Valor Martínez, C. (2003). Responsabilidad social en la empresa, concepto, medición y desarrollo en España. ICE Boletín Económico, (2755), 7-19.

Femenia, N. (2014). Una teoría posmoderna de conflictos sociales. Inter-mediación. Transformación de conflictos en el mundo hispano. http://www.inter-mediacion.com/teoria-postmoderna-de-conflictos-sociales/[Fecha de consulta, 02/07/2016]

Femenia, N. (2015). Manejo de los conflictos en las organizaciones. Foro de profesionales Latinoamericanos de Seguridad. http://www.forodeseguridad.com/artic/ admin/5232.htm [Fecha de consulta, $12 / 09 / 2015]$ 
Fernández Fernández, J. L. \& Sanjuan, A. B. (2012). La teoría del Stakeholder o de los Grupos de Interés, pieza clave de la RSE, del éxito empresarial y de la sostenibilidad. Revista Internacional de Investigación en Comunicación, 6(6), 130-143.

Freeman, R. E. (1984). Strategic Management.A stakeholder approach. Mershfield: Pitman Publishing.

Galtung, J. (2003). Paz por medios pacíficos. Paz y conflicto, desarrollo y civilización. Bilbao: Gernika Gogoratuz.

García-Longoria, M. P. (2002). La mediación escolar, una forma de enfocar la violencia en las escuelas. Cuadernos de Trabajo Social, (10), 319-327.

Gezuraga, I. O. (2014). Más allá del arbitraje cooperativo: la mediación cooperativa. Sobre la necesidad de fomentarla en el ordenamiento jurídico español a la luz del Real Decreto-Ley 5/2012, de 5 de marzo, de mediación en asuntos civiles y mercantiles. Revista Vasca de Economía Social-GizarteEkonomiaEuskalAldizkaria, (8), 11-141.

González, J. \& Coquies, U. E. (2011). Las cooperativas y sus prácticas de resolución de conflictos desde el enfoque cualitativo. Revista latinoamericana de Metodología de la Investigación Social, (2), 44-58.

Iglesias Ortuño, E., Palmer Marrero, J. \& Perona Mejías, A. (2016). Conflictos en el entorno de trabajo. La mediación en la empresa cooperativa. En M. Avilés Hernández \& V. Meseguer Sánchez (Dirs.), Empresas, derechos humanos y RSC. Pamplona: Aranzadi.
Laville, J. L. \& Nyssen, M. (2001). Los Servicios Sociales entre las asociaciones, el Estado y el Mercado. En J. L. Laville (Coord.), Economía Social y Servicios Sociales (pp. 18-35). Valencia: CIRIEC España.

Lechat, N. M. (2003). Economía Moral. En A. D. Cattani (Coord.), La otra economía (pp. 165-172). Brasil: Fundación OSDE.

Lederach, J. P. (2000). El abecé de la paz y los conflictos. Madrid: Catarata.

Levesque, B. \& Mendell, M. (1999). L'Économie sociale au Quebec: éléments théoriques et empiriques pour le débat et la rechercha. Cahier du CRISES, (9908), 31-65.

Levesque, B., Bourques, G. \& Forgues, E. (2001). La nouvelle sociologie economique. Paris: Desclée de Brouwer.

Lisboa, A. (2001). A socioeconomiasolidáriadiante de grande transformacao. CianciasSociais UNISINOS, 37(159), 27-57.

Loaiza Ospina, D. A. (2011). Algunos aportes de la gestión humana al desarrollo de la estrategia y competitividad de la organización. Revista Pensamiento Americano, 4(7), 17-21.

Lozano, J. M. (1999). Ética y empresa. Madrid: Trotta.

Mance, E. (2001). A consistencia das redes solidárias. Ciencias Sociais UNISINOS, 37(159), 177-204.

Maslow, A. H. (1991.) Motivación y personalidad. Madrid: Ediciones Díaz de Santos.

Monzón Campos, J. L. (2006). Economía social y conceptos afines: fronteras borrosas $y$ ambigüedades copceptuales del Tercer 
Sector. Revista de Economía Pública, Social y Cooperativa, (56), 9-24.

Monzón, J. L. \& Defourny, J. (1992). La Economía Social: entre Economía Capitalista y Economía Pública. Valencia: CIRIEC-España.

Munduate, L. \& Medina, F. J. (2005). Gestión del Conflicto, Negociación y Mediación. Madrid: Pirámide.

Navarro, P. (1996). El fenómeno de la complejidad social humana. Curso de Doctorado Interdisciplinar de Sistemas Complejos. Facultad de Informática de la UPV. San Sebastián. http://home.dsoc.uevora. pt/ eje/hologramasocial.html [Fecha de consulta 6/08/2016]

Ortuño Muñoz, J. P. (2003). El Libro Verde sobre las ADR en el ámbito civil y mercantil. Iuris-La Ley, (77), 42-48.

Palacio, J. R. \& Climent, V. (2008). La innovación social en la empresa. El caso de las cooperativas y de las empresas de Economía Social en España, No 368, 187-196.

Peña Yáñez, M. A. (2007). El equipo de mediación como elemento auxiliar del juez de familia. En Consejo General del Poder Judicial. Alternativas a la judicialización de los conflictos. Madrid.

Putnam, R. D. (1993). The prosperous community: social capital and public life. American Prospect, 13, 25-42.

Ramos Pérez, M. E. (2006). La gestión de conflictos en cooperativas. Acciones e Investigaciones Sociales, (22), 105-155.
Redorta Lorente, J. (2007). Entender el conflicto. Barcelona: Paidós.

Rojas Chadid, J. E. (2009). Crisis, academia y solución gerencial androcrática para la empresa contemporánea. Revista Pensamiento Americano, 2(3), 39-49.

Rubin, J. Z., Pruitt, D. G. \& Hee Kimm, S. (1994). Social Conflict. Escalation, Stalemate, and Settlement. New York. McGraw-Hill.

Sanchís Palacio, J. R. \& Campos Climent, V. (2008). La innovación social en la empresa: el caso de las cooperativas y de las empresas de economía social en España. Economía industrial, (368), 187-196.

Singer, P. (2003). Economía Solidaria. En A. D. Cattani (Coord.), La otra economía (pp. 199-212). Brasil: Fundación OSDE.

Torrego, J. C. (2003). Resolución de conflictos desde la acción tutorial. Madrid: Consejería de Educación, Dirección de Ordenación Académica.

Touzard, H. (1980). La mediación y la resolución de conflictos. Barcelona: Herder.

Vázquez Presencio, M. P. (2007). El colapso Judicial. Estudios de Derecho Judicial, (136), 85-98.

Vinyamata, E. (1999). Manual de prevención y resolución de conflictos. Barcelona: Ariel.

Wautier, A. M. Economía Social en Francia. En A. D. Cattani (Coord.), La otra economía (pp. 187-19). Brasil: Fundación OSDE. 